\title{
Exploring Consumers' Understanding and Evaluation of their Ethical Consumption and Disposition
}

\author{
RayeCarol Cavender ${ }^{1 *}$, Alexandra Howell ${ }^{2}$, Julie L Hillery ${ }^{3}$, V Ann Paulins ${ }^{4}$ and Iva Jestratijevic ${ }^{3}$ \\ ${ }^{1}$ University of Kentucky, USA \\ ${ }^{2}$ Meredith College, USA \\ ${ }^{3}$ The Ohio State University, USA \\ ${ }^{4}$ Ohio University, USA
}

*Corresponding author: RayeCarol Cavender, Assistant Professor, Department of Retailing and Tourism Management, School of Human Environmental Sciences,

University of Kentucky, USA.

Received Date: March 29, 2019

Published Date: April 02, 2019

\section{Introduction}

The apparel industry is in the midst of a watershed moment for corporate sustainability initiatives, with a growing number of organizations setting measurable sustainability targets across their supply chains (e.g., sourcing, manufacturing, logistics, operations) where the bulk of the ecological and social impact of the sector lies [3]. Despite the increased corporate accountability for the company-facing responsibilities of sustainability, the consumer group that is actively engaged in sustainable consumption, or "consumption that simultaneously optimizes the environmental, social, and economic consequences of acquisition, use, and disposition in order to meet the needs of both current and future generations," remains a niche segment [27].

Multiple barriers exist to the mainstream adoption of sustainable consumption among consumers, with the first being the proliferation of verbiage related to these behaviors (e.g., "green," “eco," "ethical," "sustainable," "slow fashion," etc.). Consumers' exposure to the range of, often inconsistent, terminology along with the trend toward corporate greenwashing has convoluted consumers' understanding of sustainability and their role in its widespread adoption [31]. This confusion is exacerbated by the general lack of knowledge and awareness about the breadth of sustainability issues, which has hindered the mobilization of a sustainable fashion system [21,6]. Another barrier to the mainstreaming of sustainable consumption is the framing of the sustainability discourse [45]. Growing media coverage of sustainability challenges (e.g., climate change, resource depletion) has increased consumer awareness about macro-level issues and company-facing responsibilities (e.g., ethical labor practices, efforts toward more sustainable supply chains, etc.). However, messages that could limit consumption, the major driver of society's economic growth has been severely limited and have failed to transfer responsibility to the consumer on a large scale $[43,48,51]$. The implications of this issue are especially apparent in the fast fashion sector where many organizations (e.g., H\&M) tout sustainability commitments in their supply chains, while appealing to customers' sustainability consciousness through programs that offer discounts for bringing their used clothing to recycle in-store [19]. Through these 'corporate greenwashing' practices, fast fashion companies have been able to avoid overhauling their inherently unsustainable business models while positioning themselves as ethically responsible among consumers [13]. What's more, these superficial appeals (i.e., greenwashing; in- store recycling programs) to engage consumers on sustainability issues further perpetuate overconsumption because consumers believe that they are taking pro-environmental action through their patronage of these brands $[6,28]$. Therefore, consumers are not prompted to consider "that purchasing is always a moral-and not simply economic-act... [and that] the consumer has a specific social responsibility, which goes hand- in-hand with the social responsibility of the enterprise" [49].

The previous example highlights "the perceived incompatibility between consumption reduction and established public policy goals, cultural values, and corporate strategies that prioritize the maintenance of economic growth, consumer sovereignty, and the uninhibited acquisition of material possessions" [28]. This sentiment is echoed by many marketing scholars who assert that successfully addressing the sustainability imperative on a large scale will require challenging the dominant social paradigm of consumerism along with a fundamental rethink of marketing's role $[28,30,35,44]$. Three major deficiencies with sustainability approaches 
have been identified across scholarly research, corporate strategies and Although all consumers are capable of adopting more sustainable policy making including, not directly focusing on the customer, not behaviors, their individual purchase motivations and decisionacknowledging the looming threats of global overconsumption and disposition, and not taking a holistic approach [7]. To that end, scholars have begun to employ a macro institutional approach that "incorporates the buyer's contribution to the solution of the social issue, rather than putting responsibility for the issue exclusively with the company" [45]. This approach emphasizes the value of an "agentic perspective on consumers as strategic, purposive actors" in the paradigm shift to a more sustainable apparel system [50].

Consumer behavior related to ethical consumption and disposition continues to be investigated across disciplines (e.g., psychology, sociology, marketing) via a range of theoretical foundations (e.g., sociality and self; expectancy-value, rational choice, moral and normative influences, contextual and situation approaches; etc.). Jackson [39] examines these approaches in a 170page report for the Sustainable Development Research Network and Peattie [28] offers an updated review in his report for the Center of Business Relationships, Accountability, and Society. The breadth of approaches to the study of ethical consumption and disposal are not explored in this manuscript. Instead, the review of literature provides an abridged discussion of the theoretical foundations that underpin this research (i.e., buyer social responsibility, 'greening' consumer) and offers insight into why these foundations may be preferable in research exploring consumers' potential for adopting more sustainable consumption behaviors $[20,30,33]$.

The present study answers the call for continued research that identifies opportunities to facilitate the social normalization of sustainable consumption among consumers $[4,21,33,44,52]$. In the absence of agreed upon definitions of ethical consumption and disposal, this research seeks to evaluate consumers' consumption and disposition practices based on their own reported definitions of these concepts. The approach to this exploratory study seeks to mitigate previously reported methodological concerns (e.g., attitude behavior gap, framing, social desirability bias) in the study of this complex relationship $[4,28,39,41]$

\section{Literature Review and Theoretical Foundation}

\section{Greening apparel consumer}

Peattie [15] stated that there is no such thing as a truly 'green' consumer, meaning that consumers are simultaneously engaging in both sustainable and unsustainable consumption behaviors. McDonald, et al. [4] dubbed this concept, 'grey consumption,' or the failure to purchase sustainable products in categories where sustainable options are available. McDonald et al. [20] describes the process by which consumers adopt more sustainable consumption behaviors as 'greening,' acknowledging that individuals' approaches to greening their lifestyles are contingent on a range of contextual influences at the micro (e.g., consumer decision-making process) and macro (e.g., societal norms) levels. Balderjahn et al. [9] refer to this process as adopting a consciousness for sustainable consumption (CSC), a gradually increasing "intention to consume in a way that enhances the environmental, social and economic aspects of quality of life."

\section{P}

$$
\begin{aligned}
& \text { well-documented, especially pertaining to apparel pur } \\
& {[6,32,56-58] \text {. Attitudes are a strong indicator of behaviors in }}
\end{aligned}
$$

making processes pose a challenge to identifying a homogenous group of green or 'greening' consumers [4]. Furthermore, "an individual consumer can have a different sustainability consciousness depending on the consumption situation"[25]. Adopting a holistic approach to exploring consumers' consumption and disposal behaviors by considering the breadth of their reported purchases (i.e., apparel, non-apparel) and behaviors (e.g., sustainable, unsustainable) is proposed as a strategy that can yield meaningful insights into consumers' sustainable consumption in an evolving market environment [4].

\section{Buyer social responsibility}

Responsibility is conceptualized as "the outcome of organized efforts by a variety of collective actors to practically rearticulate the ordinary ethical dispositions of everyday consumption" [53]. Luchs, et al. [41] refer to this process as 'responsibilities.' In order for a paradigm shift toward sustainable consumption to occur in the mainstream consumer market, the concept of responsibility will be "valuable as it describes the longitudinal processes that turn collective social issues into issues of personal responsibility" [41]. Buyer social responsibility (BSR), the consumer counterpart to corporate social responsibility, necessitates that consumers consider both their individual needs and the social consequences that arise from their purchase and disposal decisions [45]. Perceived importance of social and environmental issues (e.g., time sensitivity), perceived marketplace influence (i.e., personal impact), increased awareness (e.g., consequences of actions), and the desire to change are just a few key drivers of consumers' BSR [41,45,48,54,55]. The role of responsibility, coupled with the role of the moral norm (i.e., perceived moral obligation), are also represented in two of the more robust frameworks that have been applied to the study of ethical consumption behavior, Schwartz's [14], Norm Activation Theory and Stern's [12,36] Value-Belief- Norm Model.

The managerial implications of this perspective indicate that a "greater focus should be placed on responsibility both as a way to identify and segment consumers, as well as something to address in promotion and communication efforts" [41]. However, companies must carefully emphasize that consumers do not bear the full responsibility of the sustainability imperative, but that this issue will be approached as a joint challenge and commitment for all institutional actors in the fashion system [34,41,50]. For the transition to a more sustainable apparel industry to accelerate, "it is crucial that companies actively communicate that consumers can contribute through their consumption behavior (ascription of responsibility) and that small steps can have cumulative substantial impacts (awareness of social impact consequences)" [45].

\section{Pro-environmental attitude-behavior gap}

The existence of a pro-environmental attitude-behavior gap is well-documented, especially pertaining to apparel purchases 6,52,56-58]. Attitudes are a strong indicator of behaviors in 
most contexts (i.e., Ajzen \& Fishbein's Theory of Reasoned Action; Ajzen's Theory of Planned Behavior) [11,59]. Despite consumers, in general, demonstrating strong and positive attitudes towards sustainability, these favorable attitudes do not always extend to their consumption and disposal practices [17,32,41]. Therefore, research suggests that, rather than focusing on attitudes toward sustainability, which are largely positive, organizations and social entities (e.g., NGOs) should ascribe a level of responsibility to consumers in order to increase their BSR and agency for conscious consumption $[38,41,45]$. This pilot study sought to mitigate social desirability bias and the attitude behavior gap through the study design with the goal of gleaning insights that can be employed in the next iteration of this research (i.e., EFA, CFA).

\section{Method}

This exploratory pilot study examined consumers understanding of their beliefs and practices related to ethical consumption and disposal based on their own reported definitions of these concepts. The study utilizes a holistic approach to identifying consumers' current and desired levels of ethical consumption/disposal, proposing that

1. All consumers exhibit both ethical and unethical behaviors and

2. That all consumers have the potential to adopt more sustainable behaviors [4,15]. The following research questions were proposed to address the study's purpose.

\section{Research Questions}

Q1: How are consumers' reported definitions of ethical consumption and disposal reflective of the commonly recognized definitions reported in existing literature?

Q2: How do consumers' reported levels of ethical consumption and disposal compare to their desired levels of ethical consumption and disposal?

Q3: How do consumers' reported levels of ethical consumption compare to their reported levels of ethical disposal?

Q4: What is the relationship between product category and consumer behavior with respect to ethical consumption and disposal?

Q5: What are consumers' goals for behavioral change related to ethical consumption and disposal?

\section{Instrument}

To address the research questions, a 17-item questionnaire that included four demographic questions was prepared. The survey was designed for ease of response, and to provide primarily qualitative data that allowed for the meaningful insights that can be obtained through open-ended responses [26]. Although openended questions and well-designed closed-ended questions can produce the same results, open-ended questions can be especially beneficial for gleaning additional insight into nascent research areas [8]. Open- ended questions were also employed in the present study to avoid the challenges that have been associated with question framing in the exploration of sustainable behavior. That is, respondents often select the response that makes them appear the most ethical (i.e., social desirability bias) regardless of whether the response is an accurate reflection of their motivation, behavior, etc. $[12,28,29,36,42]$. The open- ended questions were also designed to mitigate the presence of the attitude-behavior gap [32] by focusing on respondents' evaluation of their ethical consumption and disposal at one point in time rather than their motivations to consume more ethically as motivation has not been found to be a significant predictor of behavior in previous research on sustainable consumption. This has led many scholars to advocate for alternative methodological approaches $[4,17,21,28]$.

Respondents were asked to consider their consumer behaviors across multiple categories including food, household furnishings, electronics, cars and other motor vehicles, clothing and accessories (including jewelry and shoes), and so on. The researchers asked participants to describe what it means to be an "ethical consumer" and to define "ethical consumer product disposal." For both ethical consumption and ethical disposal, respondents were asked to rate their perceived levels of ethical behavior (i.e., 0-10 scale with 0 being very unethical and 10 being very ethical) based on the definitions they provided. Respondents also answered a closed-ended question that gauged their levels of satisfaction with their current consumption and disposal behaviors (i.e., more ethical than I need to be, just right in terms of ethical behavior, less ethical than I wish to be). Those who indicated a desire to change their behaviors were asked to provide up to five goals for change. Finally, participants responded to open-ended questions that probed more deeply into the rationale behind their ratings, barriers to the adoption of more ethical behaviors, and perceived distinctions in their ethical behavior across product categories. To improve internal validity of the qualitative responses, the quantitative responses were analyzed using the Statistical Package for the Social Sciences (SPSS).

\section{Data collection}

Surveys were prepared for electronic distribution using the Qualtrics tool. Following IRB approval, data collection occurred from October 2 to October 27, 2018. Surveys were disseminated via the social media platforms Facebook $₫$ and Twitter $\AA$ as well as through emails directed at select large and diversely populated courses offered at the authors' institutions. The multiple authors' geographic diversity provided opportunity for convenience sampling that was also aimed at maximizing broad sampling. After the 25-day data collection window closed, 54 complete and usable surveys had been obtained.

\section{Sample population}

Despite attempts to reach a diverse sample population, the respondents were primarily white (81\%) females (89\%) of traditional college age (mean age $=23$ ). Participants' ages ranged from $18-54$, with a median age of 20 , the mode being 18 , and $78 \%$ reporting that they were currently college students. 


\section{Data analysis and results}

Content analyses was employed to analyze the open-ended questions and ascertain consumers' understanding of ethical consumption and product disposal. To achieve rigor and credibility in the data analysis, the researchers employed Bengtsson's [23] four content analysis stages of decontextualization, recontextualization, categorization and compilation.

Definitions previously reported in the literature were used as markers for comparison [6,18,21,41,47]. Quantitative data analyses were performed using the SPSS tool. To determine whether consumers' self-ratings on ethical consumption matched their desired levels of ethical consumption, the researchers compared the reported ratings with consumers' assessments of whether they were

a) More ethical than they believe the need to be,

b) Just right, or

c) Less ethical than they wish to be (RQ2). Paired t-tests were administered to determine whether consumers' reported levels of ethical consumption matched their reported levels of ethical product disposal (RQ3). Descriptive analyses provided insight into this comparison. Descriptive analyses also provided insight into the way's consumers differentiated the ethical behaviors of consumption and disposal according to product category. To further explore the ways consumers' behaviors differed by product category, the researchers performed content analysis of the descriptions they provided (RQ4).

\section{Results and Discussion}

\section{Reported definitions of ethical consumption and disposal (RQ1)}

Tadajewski M, et al. [10] suggest that consumers often possess a conceptual and broad understanding of sustainability topics (e.g., "recycled," "organic), referred to as knowledge abstractness. In contrast, few consumers possess knowledge specificity, or the ability to recall brand names, product names, and most importantly, the ability to evaluate "lifecycle considerations" in their consumption and disposal decisions. Those with the highest levels of knowledge specificity make purchasing decisions by evaluating the ethical impact of the product across its lifecycle (i.e., sourcing, production, transportation) prior to the point of purchase and their own responsibility in mitigating the environmental and social impact of the product post-purchase (i.e., consumption, care, disposal) [10]. The researchers considered these levels of understanding in the content analysis for RQ1.

\section{Reported definitions of ethical consumption}

To get a better understanding of how consumers define "being ethical," respondents were asked the open-ended question, "What does it mean to be an ethical consumer?" Responses were framed in a general manner and for the most part, did not refer to specific product categories. For example, the following answer best reflects the types of categories mentioned when describing an ethical consumer:
Being an ethical consumer means considering all aspects of the production of an item- from the treatment of those who harvested or produced the raw materials, to the environmental impact of using the particular materials and methods, to the amount and type of packaging, and durability of the item(s).

In other words, being ethical was described in terms of the production and procurement of raw materials, product manufacturing, packaging, consideration for buying durable items and making purchases that are "eco-friendly" without reference to the specific product. Related to the idea of durability, many responses mentioned buying products that are high quality so that they last longer. Additionally, many respondents mentioned the importance of buying products from companies that treat both workers (e.g., wages, safety, hours) and animals (i.e., sourcing practices, no animal testing, alternative materials) ethically. Specifically, one respondent stated that ethical consumers buy from companies whose products are produced under good ethical circumstances by workers who are paid fairly. In summarizing how respondents defined an ethical consumer, the following quote captures the general sentiment:

Consider where the product came from; how the workers or animals are treated, do they donate/support things. In general, just be aware of where your money is going and how the company handles it and how they handle their product, workers, and what not.

\section{Reported definitions of ethical disposal}

Respondents indicated that recycling as a general concept was a method of ethical and/or sustainable disposal. There were varied interpretations and meanings of recycling. However, a majority of responses to the question, "Product disposal is a component of consumption for many purchased items. What do you consider to be disposal? Please use examples to help explain your definition" indicated that recycling was part of the disposal process. Several respondents indicated that the adage "reduce, reuse, recycle" was most indicative of ethical and/or sustainable disposal. Twentyseven respondents utilized the word "recycle" or "recycling" to describe disposal. Of the 27 qualitative responses some explored the meaning of recycling in a more substantial manner:

The basics of Reduce, Reuse, and recycle. with a preference for reduction of the necessity to dispose of anything in volume. Also, consideration of impact on environment for location and means of disposal and recycling efforts. An example: If I were to buy a tale [sic], I would seek to buy one that would last and serve my purposes for the longest duration possible. Additionally, if it ceased to be of use to me, I would try to find another use or another user. Once the table was no longer [sic] functional (too decrepit to use or repair) I would try to repurpose the wood. Failing that, I would likely incorporate it in a fire such that the waste was reduced to ash.

Other responses indicated a more general belief and understanding of recycling. One respondent stated, when possible, reuse, upcycle, or recycle a product. Other responses to this question were more specific to product categories such as containers, plastics, and packaging as well as clothing. 
The population sampled in this survey likely connects to recycling most readily because the majority of respondents were college students. Nielsen reported findings from a global study indicating that two large generational cohorts, Millennials (born 1980-1994) and Generation Z (born 1995-2015), are more willing to purchase ethically and sustainably produced products, prefer to support companies that are socially and environmentally responsible, and favor recycling and other means of ethical disposition [5]. Therefore, the favorable responses toward sustainable disposal behaviors are consistent with previous research.

When discussing containers, plastics, and packaging, respondents also indicated other consumption behaviors that would limit disposal of products such as buying in bulk or utilizing reusable containers for food and beverages. There was also a general thematic response about mindfulness of product usage as an indication that one is participating in ethical/sustainable product disposal. Being mindful of how one disposes of products that are done using. ex. Recycling Recycle if applicable, donate clothes/ pass on, and try to limit trash. Reusing, donating, consigning, and upcycling clothing items were also noted by respondents as ways to mitigate wasteful disposal of apparel.

\section{Reported and desired levels of ethical consumption and disposal (RQ2)}

Reported and desired levels of ethical consumption: When asked to rate themselves on a scale of 1 (i.e., very unethical) - 10 (i.e., very ethical) in terms of how well they matched their own definitions of an ethical consumer, the scores ranged from 1-10 with a mean score of 5.7. When asked to justify their self-rating on ethical consumption, respondents identified barriers to adopting more ethical consumption practices, including the need for convenience (e.g., ethically- produced items were not always readily available), the desire to save money (e.g., ethically- produced items were more expensive), and the lack of time to thoroughly educate themselves on what they were buying (e.g., information on ethically-produced products was not readily available; time constraints). The majority of respondents (94\%) reported that they want to change their behavior related to ethical consumption.

To determine how consumers' self-ratings on ethical consumption compared with their desired levels of ethical consumption, the researchers compared the reported ratings with consumers' assessments of whether they were

(a) more ethical than they believe the need to be,

(b) just right, or

(c) less ethical than they wish to be.

A majority (76\%) of respondents indicated that they are less ethical consumers than they believe they need to be, with 22 percent reporting "just right" and one respondent (2\%) responding with, "I am more ethical than I believe I need to be." Using cross tabulation analysis, the researchers determined that all consumers who rated their ethical consumption behavior from 1-8 on the 10 -point scale expressed a desire to change their behavior. The three respondents that reported ethical consumption levels of 9 and 10 were the only participants who did not indicate a desire to change their consumption behavior. Similarly, all consumers who rated themselves "less ethical than they want to be" ( $n=41$; $76 \%$ ) indicated that they desire to change their behavior. Of the consumers who rated themselves "just right," 75 percent expressed a desire to change their behavior to become more ethical. Only one person provided a self-rating of "more ethical than I need to be," and even that respondent indicated a desire to adopt more ethical consumption practices.

Reported and desired levels of ethical disposal: Respondents expressed less motivation to change their product disposal behaviors than their consumption behaviors, with only $66.7 \%$ of survey participants indicating that they want to make a change. Eleven of the 17 respondents indicated that they feel their disposal practices are "ethical enough" and do not need modification. This is interestingly juxtaposed against the openended responses for wanting to change one's disposal habits. Some respondents had blanket goals, do better is my only goal, whereas others had more formulated ideas for how to improve, 1) Buy less/ only if I need it. 2) Try more reusing and upcycling. 3) Research more into ethical disposal of different products. Similar to the findings on consumption, clothing was the most frequently cited product category in which participants sought to improve their disposal habits. Again, upcycling, consigning, and reusing were all listed as potential possibilities to improve one's ethical disposal practices.

When asked to justify their self-rating on ethical disposal, the barriers to change regarding ethical disposal were less obvious based on the respondents in this study. There was also an element of cognitive dissonance among respondents as they felt positive about their behaviors and did not indicate a need for change, while simultaneously listing a number of ways they could possibly change or improve their behavior. Beyond clothing as a product category, the responses lacked clarity on what would qualify as ethical disposal for other products. Some respondents discussed the process of composting food waste as a means of ethical disposal. Although, other product categories were mentioned for recycling, they were not mentioned or listed when discussing behavioral improvements for ethical disposal. Respondents also used "reduction" as a method to engage in ethical consumption, physically buying and using less in lieu of engaging in or exploring any ethical disposal practices.

The participants in this survey demonstrated a general understanding of ethical disposal supported by their perceptions of what ethical disposal is and how their behaviors can be modified to improve ethical disposal. While the results are certainly not generalizable, this research suggests that disposal or "reuse and 
recycle" are important elements of the ethical consumption process. Importantly, respondents in this survey did indicate clothing as a product that can be more easily recycled or disposed of in ethical ways. Because the average American generates 84 pounds of textile waste per year [37], insights that support the adoption of more ethical disposal practices will likely help reduce this number.

\section{Comparison of reported levels of ethical consumption and disposal (RQ3)}

In response to RQ3, consumers' perceived levels of ethical consumption, rated on a scale of $1=$ unethical to $10=$ highly ethical, matched their reported levels of ethical product disposal (rated on the same 10-point scale). That is, there was not a significant difference between the self-ratings of consumers' ethical consumption $(\bar{x}=5.79)$ and ethical disposal $(\bar{x}=6.02)$ behaviors $(t=$ $-0.842 ; p=0.404$ ). In terms of overall comparative ratings, more of the respondents reported higher levels of ethical disposal behavior (11 consumers rated themselves from 8-10 and 7 rated themselves from 1-3) compared to ethical consumption behavior ( 6 consumers rated themselves from 8-10 and 4 rated themselves from 1-3). These results support the notion that there is more opportunity to change (improve) ethical consumption, compared to product disposal.

\section{Relationship between product category and consumer behavior with respect to ethical consumption and disposal (RQ4)}

Clothing was mentioned most frequently as the product category where consumers practice ethical disposal. This was followed by plastics and then food and cardboard. The least mentioned items (1 time only) were paper, glass, food containers/utensils, cigarette butts, and Styrofoam, which is not actually recyclable. The method of disposal for clothing reflected responses to the previous question, reusing, donating, consigning, or upcycling as a means of ethical disposal. This finding aligns with the growing popularity of the clothing consignment trend, especially app-based consignment platforms that make this process even easier by eliminating the task of transporting clothing to a local consignment shop. Consignment also offers an immediate financial benefit compared to donating used clothing to a local charity.

\section{Goals for behavioral change toward more ethical consumption and disposal (RQ5)}

Only five of the respondents reported that they did not want to change their consumption behavior to be more ethical, while the majority $(90.5 \%)$ reported a desire to change. For the latter group, when asked to identify some goals for becoming more ethical, those goals were directly related to the respondents' definitions of being an ethical consumer. Specifically, these included: limiting the purchase of clothing that is made with unethical working practices, eating meat from 'good, local sources,' limiting consumption of unneeded things, and considering quality over quantity. One interesting observation in these responses is the specificity of the product categories that were mentioned. The majority of the goals mentioned for behavioral changes involved clothing and food. This is particularly interesting because when these same respondents were asked to identify the product categories where they were most "ethical" or conscious of their own consumer behavior, the majority reported the same categories (i.e., clothing, food) in the same order of importance. Since these findings seem to be contradictory, they need merit further investigation. It is also interesting to note that when defining an ethical consumer, the responses were framed in generalities and not specific to any particular products. However, when asked about becoming "more ethical" many respondents referred to specific categories.

Eighteen respondents reported that they did not want to change their disposition behavior to be more ethical, while the majority (66.7\%) reported a desire to change. This finding also merits further investigation. A major sustainability target for the global fashion industry is the move to a circular economy, a system that leverages innovation to "cut waste and minimize negative impact, replacing the traditional linear model in which products are cheaply made, consumed and then disposed" [46]. An integral step in advancing toward a circular economy is stopping post-consumer waste (e.g., clothing, footwear, household textiles, etc.) from going to landfills, a feat that requires a joint commitment by the apparel industry and its consumers [21,40]. While many consumers report that they do recycle non-apparel products (e.g., aluminum, glass), barriers exist related to apparel recycling, including the lack of awareness about how to recycle clothing that is not suitable for the second-hand market or for donation $[3,18,47]$. This dilemma may help explain survey respondents' perceptions about their disposition behaviors and desire for change as many consumers have a better understanding of recycling for non-apparel products than non-apparel. Many consumers are also unaware of the strain that discarded clothing is putting on landfills worldwide. A 2018 report by the Global Fashion Agenda found that, "73 percent of the world's clothing ends up in landfills, while less than 15 percent of clothes are recycled and less than 1 percent of material used to produce clothing is recycled into new clothing" [22]. While consumers are becoming more cognizant of the negative impacts (e.g., social, environmental, economic) of overconsumption, a knowledge gap still exists regarding consumers' options for conscious clothing disposal compared to non-apparel product categories $[2,47]$. More education on the purpose and goals of the circular economy, options for clothing recycling, and the impact of discarded clothing on landfills may make consumers reconsider whether they are satisfied with their current disposition behaviors across all product categories, including clothing, or whether they desire behavioral change toward more ethical disposition.

\section{Conclusion}

A systemic transformation of the dominant social paradigm toward more ethical consumption and disposition will require a concerted effort by organizations and consumers [34,50]. Mobilization of this movement at the consumer level has been hindered by a lack of active communication from the array of retailers whose operations support the sustainability mission and a failure to ascribe responsibility to consumers for their 
role in addressing the sustainability imperative. The complexity of consumer-based research on sustainable consumption has been well-documented in the literature along with the call for a more holistic approach that considers all of consumers' consumption and disposal behaviors, both ethical and unethical, across product categories. Research of this kind can be useful in mainstreaming sustainable consumption as all consumers have the potential to adopt more sustainable practices. This study provides a unique launching pad to build a broader and more inclusive study about the process of ethical consumption from purchase, use, care, to disposal. The findings demonstrate that there is a unique dissonance between what consumers believe about themselves and their functional behaviors. Building upon this finding can help practitioners better understand how to market and sell products to engage consumers in bringing their believed behaviors to fruition, and ultimately, creating a net positive impact on the environment.

Limitations existed in this study including sample size, age range, gender, and racial composition. Given the small sample size ( $\mathrm{n}=54$ ), it is difficult to make broad generalizations about one's understanding of ethical consumption and disposal. This pilot study does provide sufficient evidence of the need to continue this exploration to fill a gap in the literature. This survey was completed by predominantly college-aged students or students enrolled in university. A sample with a broader age range may provide more nuanced evidence about ethical consumption and disposal practices. Similarly, sampling populations with diverse gender and racial compositions will provide a clearer picture of beliefs and practices about ethical consumption and disposal.

Future research studies should be more inclusive of age, gender, and racial demographics to provide a more representative picture of the current U.S. population. Beyond the population sample, the breadth should be expanded to include steps of consumption between purchase and disposal. Future research should include the intermediary consumer activity of "product care" to explore how ethics factor into decisions about product use and maintenance after consumption and before disposal. Additionally, the exploration of the role of ethics in consumer behaviors should expand to products beyond 'extensions of the body'- to include home furnishings, household products (including cleaning products), electronics and automobiles.

\section{Acknowledgement}

None.

\section{Conflict of Interest}

No conflict of interest.

\section{References}

1. Prothero A, Dobscha S, Freund J, Kilbourne WE, Luchs MG, et al. (2011) Sustainable consumption: Opportunities for consumer research and public policy. Journal of Public Policy \& Marketing 30(1): 31-38.

2. Jung S, Jin B (2016) From quantity to quality: Understanding slow fashion consumers for sustainability and consumer education. International Journal of Consumer Studies 40(4): 410-421.
3. Global Fashion Agenda (2018) Pulse of the fashion industry.

4. McDonald S, Oates CJ, Alevizou PJ, Young CW, Hwang K (2012) Individual strategies for sustainable consumption. Journal of Marketing Management 28(3-4): 445-468.

5. (2015) Green generation: Millennials say sustainability is a shopping priority.

6. McNeill L, Moore R (2015) Sustainable fashion consumption and the fast fashion conundrum: Fashionable consumers and attitudes to sustainability in clothing choice. International Journal of Consumer Studies 39(3): 212-222

7. Sheth JN, Sethia NK, Srinivas S (2011) Mindful consumption: a customercentric approach to sustainability. Journal of the Academy of Marketing Science 39(1): 21-39.

8. Schuman H (2008) Methods and meaning in polls and surveys. Harvard University Press, Cambridge, USA, p. 232

9. Balderjahn I, Buerke A, Kirchgeorg M, Peyer M, Seegebarth B, et al. (2013) Consciousness for sustainable consumption: scale development and new insights in the economic dimension of consumers' sustainability. AMS review 3(4): 181-192.

10. Tadajewski M, Wagner-Tsukamoto S (2006) Anthropology and consumer research: Qualitative insights into green consumer behavior. Qualitative Market Research: An International Journal 9(1): 8-25.

11. Ajzen I, Fisbbein M (1974) Factors influencing intentions and the intention-behavior relation. Human relations 27(1): 1-15.

12. Stern PC (2000) Toward a coherent theory of environmentally significant behavior. Journal of Social Issues 56(3): 407-424.

13. Bain M (2017) Fast fashion's sad cycle of compulsive shopping, guilt, and regret has spread to Asia. Quartz.

14. Schwartz S (1977) Normative influences on altruism. Advances in experimental social psychology 10: 222-279.

15. Peattie K (2001) Golden goose or wild goose? The hunt for the green consumer. Business Strategy and the Environment 10: 187-199.

16. Barnett C, Clarke N, Cloke P, Malpass A (2005) The political ethics of consumerism. Consumer Policy Review 15(2): 45-51.

17. Joy A, Sherry JF, Venkatesh A, Wang J, Chan R (2012) Fast fashion, sustainability, and the ethical appeal of luxury brands. Fashion Theory 16(3): 273-295

18. Morgan LR, Birtwistle G (2009) An investigation of young fashion consumers' disposal habits. International Journal of Consumer Studies 33(2): 190-198.

19. Wicker A (2016) Fast fashion is creating an environmental crisis. Newsweek.

20. Kotler P (2011) Reinventing marketing to manage the environmental imperative. Journal of Marketing 75(4): 132-135.

21. Ertekin ZO, Atik D (2015) Sustainable markets motivating factors, barriers, and remedies for mobilization of slow fashion. Journal of Macromarketing 35(1): 53-69.

22. O'Connor T (2018) Fashion's 7 priorities to achieve sustainability. Business of Fashion

23. Bengtsson M (2016) How to plan and perform a qualitative study using content analysis. Nursing Plus Open 2: 8-14.

24. Kotler P (2011) Reinventing marketing to manage the environmental imperative. Journal of Marketing 75(4): 132-135.

25. Balderjahn I, Peyer M, Seegebarth B, Wiedmann KP, Weber A (2018) The many faces of sustainability-conscious consumers: A categoryindependent typology. Journal of Business Research 91: 83-93.

26. Smith JA (Edts) (2007) Qualitative psychology: A practical guide to research methods. Thousand Oaks, CA: Sage Publications, London.

27. Phipps M, Ozanne LK, Luchs MG, Subrahmanyan S, Kapitan S, et al. (2013) Understanding the inherent complexity of sustainable consumption: A 
social cognitive framework. Journal of Business Research 66(8): 12271234.

28. Peattie K (2010) Green consumption: behavior and norms. Annual Review of Environment and Resources 35: 195-228.

29. Cleveland M, Kalamas M, Laroche M (2005) Shades of green: linking environmental locus of control and pro-environmental behaviors. Journal of Consumer Marketing 22(4): 198-212.

30. McDonagh P, Prothero A (2014) Sustainability marketing research: Past, present and future. Journal of Marketing Management 30(11-12): 1186-1219.

31. Harris F, Roby H, Dibb S (2016) Sustainable clothing: challenges, barriers and interventions for encouraging more sustainable consumer behaviour. International Journal of Consumer Studies 40(3): 309-318.

32. Perry A, Chung T (2016) Understand attitude-behavior gaps and benefitbehavior connections in Eco-Apparel. Journal of Fashion Marketing and Management 20(1): 105-119.

33. Armstrong Soule CA, Reich BJ (2015) Less is more: Is a green demarketing strategy sustainable? Journal of Marketing Management 31(13-14): 1403-1427.

34. Hopkinson GC, Cronin J (2015) When people take action... Mainstreaming malcontent and the role of the celebrity institutional entrepreneur. Journal of Marketing Management 31(13-14): 1383-1402.

35. Torelli CJ, Monga AB, Kaikati AM (2012) Doing poorly by doing good: Corporate social responsibility and brand concepts. Journal of Consumer Research 38(5): 948-963.

36. Stern PC, Dietz T, Abel T, Guagnano GA, Kalof L (1999) A value-belief-norm theory of support for social movements: The case of environmentalism. Human Ecology Review 6(2): 81-97.

37. Ross M (Producer), Morgan A (Director) (2015) The True Cost (Motion Picture), USA: Life is my Movie Entertainment.

38. Park J, Ha S (2014) Understanding consumer recycling behavior: Combining the theory of planned behavior and the norm activation model. Family and Consumer Sciences Research Journal 42(3): 278-291.

39. Jackson T (2005) Motivating sustainable consumption: A review of evidence on consumer behaviour and behavioural change. Sustainable Development Research Network 15: 1-171.

40. (2018) Regain app fashion app launches.

41. Luchs MG, Phipps M, Hill T (2015) Exploring consumer responsibility for sustainable consumption. Journal of Marketing Management 31(13-14): 1449-1471.

42. Hiller AJ (2010) Challenges in researching consumer ethics: A methodological experiment. Qualitative Market Research: An International Journal 13(3): 236-252.
43. Park H, Kim YK (2016) An empirical test of the triple bottom line of customer-centric sustainability: The case of fast fashion. Fashion and Textiles 3(1): 25-43.

44. Sodhi K (2011) Has marketing come full circle? Demarketing for sustainability. Business Strategy Series 12(4): 185.

45. Ingenbleek PT, Meulenberg MT, Van Trijp HC (2015) Buyer social responsibility: A general concept and its implications for marketing management. Journal of Marketing Management 31(13-14): 1428-1448.

46. Fernandez C (2018) How can fashion embrace the circular economy? Business of Fashion.

47. Norum PS (2017) Towards sustainable clothing disposition: Exploring the consumer choice to use trash as a disposal option. Sustainability 9(7): 1187-1201.

48. Hill J, Lee H H (2012) Young generation Y consumers' perceptions of sustainability in the apparel industry. Journal of Fashion Marketing and Management 16 (4): 477-491.

49. LaRocca D (2014) Brunello Cucinelli: A humanistic approach to luxury, philanthropy, and stewardship. Journal of Religion and Business Ethics 3(1): 1-26.

50. Scaraboto, D, Fisher, E (2013) Frustrated fatshionistas: An institutional theory perspective on consumer quests for greater choice in mainstream markets. Journal of Consumer Research 39(6): 1234-1257.

51. Dach L, Allmendinger, K (2014) Sustainability in corporate communications and its influence on consumer awareness and perceptions: A study of H\&M and Primark. Procedia-Social and Behavioral Sciences 130: 409-418.

52. Zaharia C, Zaharia I (2014) The greening of consumer culture. Economics, Management and Financial Markets 9(1): 136-141.

53. Barnett C, Clarke N, Cloke P, Malpass, A (2005)The political ethics of consumerism. Consumer Policy Review 15(2): 45-51.

54. Bendell, J, Thomas, L (2013) The appearance of elegant disruption Theorising sustainable luxury entrepreneurship. Journal of Corporate Citizenship 52: 9-25.

55. Leary RB, Vann RJ, Mittelstaedt, JD (2017) Leading the way: Motivating environmental action through perceived marketplace influence. Journal of Business Research 79: 79-89.

56. Kim HS, Damhorst ML (1998) Environmental concern and apparel consumption. Clothing and Textiles Research Journal 16(3): 126-133.

57. Joung HM (2014) Fast-fashion consuers' post-purchase behaviors. International Journal of Retail \& Distribution Management 42(8): 688-697

58. Sadachar A, Feng F, Karpova EE, Manchiraju S (2016) Predicting environmentally responsible apparel consumption behavior of future apparel industry professionals: The role of environmental apparel knowledge, environmentalism and materialism. Journal of Global Fashion Marketing 7(2):76-88.

59. Ajzen I (1991) The theory of planned behavior. Organizational behavior and human decision processes 50(2):179-211. 